УДК 332.144

ББК 65.054

DOI $10.31554 / 2222-9175-2019-36-233-237$

А. З. Убонова, С. Б. Цыбикдоржиев

АНАИИЗ АОСТИЖЕНИЯ ПРОГНОЗНЫХ ПОКАЗАТЕАЕЙ
СОЦИА БНО-ЭКОНОМИЧЕСКОГО РАЗВИТИЯ
РЕСПУБАИКИ БУРЯТИЯ

Рассмотрены среднесрочные прогнозы социально-экономического развития Республики Бурятия на периоды: 2016-2018, 2017-2019, 2018-2020 гг., а также долгосрочный прогноз до 2030 г. Проанализированы основные экономические показатели. Выявлены отклонения фактических значений от прогнозных.

Ключевые слова: долгосрочный прогноз, среднесрочный прогноз, документы стратегического планирования, Республика Бурятия, социально-экономическое развитие.

D. Z. Ubonova, S. B. Tsybikdorzhiev

\title{
ESTIMATION OF ACCURACY OF THE PREDICTIONS \\ OF SOCIO-ECONOMIC DEVELOPMENT OF THE REPUBLIC OF BURYATIA
}

The medium-term forecasts of the socio-economic development of the Republic of $\mathrm{Bu}$ ryatia for the periods from 2016-2018, 2017-2019, 2018-2020, as well as the long-term forecast up to 2030 are comprehensively reviewed. The main economic indicators are analyzed. Deviations of the actual values from the forecast are revealed.

Keywords: long-term forecast, medium-term forecast, the Republic of Buryatia, documents of strategic planning, socio-economic development.

\рогнозирование является важнейшим элементом системы стратегическопредставлений о рисках, направлениях, результатах и показателях социально-экономического развития страны и ее регионов.

В соответствии с принятым в 2014 г. Федеральным законом «О стратегическом планировании в Российской Федерации» к документам стратегического планирования, разрабатываемым на уровне субъекта Российской Федерации в рамках прогнозирования, относятся [Федеральный закон...]:

- прогноз социально-экономического развития субъекта Российской Федерации на долгосрочный период;

- прогноз социально-экономического развития субъекта Российской Федерации на среднесрочный период;

- бюджетный прогноз субъекта Российской Федерации на долгосрочный период.

УБОНОВА Дарима Зориктоевна - младший научный сотрудник отдела региональных экономических исследований Федерального государственного бюджетного учреждения науки «Бурятский научный центр СО РАН» (Улан-Удэ, Россия). Е-mail: darimaub@mail.ru.

ЦЫБИКДОРЖИЕВ Саян Баирович - младший научный сотрудник отдела региональных экономических исследований Федерального государственного бюджетного учреждения науки «Бурятский научный центр СО РАН» (Улан-Удэ, Россия). Е-mail: orei.bnc@mail.ru. 
С учетом прогнозов разрабатываются другие документы стратегического планирования, включая стратегии социально-экономического развития субъектов Российской Федерации.

Принятие указанного выше закона в целом позволило упорядочить процесс прогнозирования на региональном уровне [Потапов и др. 2015]. Вместе с тем этот документ является рамочным. В нем отражены лишь общие положения и не отражены конкретные процедуры прогнозирования, которые и определяют эффективность данного процесса.

Одной из актуальных проблем прогнозирования является недостаток или даже отсутствие анализа достижения прогнозных показателей, который необходимо проводить для выявления возможных причин отклонения фактических значений параметров от заложенных в прогнозе.

Авторами проведен анализ реализации ряда прогнозов социально-экономического развития Республики Бурятия, включая долгосрочный и среднесрочные прогнозы.

В 2013 г. был утвержден долгосрочный прогноз социально-экономического развития Республики Бурятия на период до 2030 г., разработанный в одном варианте [Постановление Правительства Республики Бурятия от 12 февраля 2013 года]. С тех пор прошло 6 лет, т. е. треть прогнозного периода (2013-2030 гг.), составляющего 18 лет. Это дает возможность проведения анализа достижения прогнозных параметров на 2018 г. (табл. 1).

Таблица 1

Показатели социально-экономического развития Республики Бурятия*

\begin{tabular}{|c|l|c|c|}
\hline № & \multicolumn{1}{|c|}{ Показатель } & $\begin{array}{c}\text { Значение показателя } \\
\text { в 2018 г. по долго- } \\
\text { срочному прогнозу }\end{array}$ & $\begin{array}{c}\text { Фактическое } \\
\text { значение показателя } \\
\text { в 2018 г.* }\end{array}$ \\
\hline 1 & $\begin{array}{l}\text { Индекс физического объема ВРП, \% } \\
\text { к 2012 г. }\end{array}$ & $123,0 * *$ & $90,4^{* *}$ \\
\hline 2 & $\begin{array}{l}\text { Индекс промышленного производства, } \\
\text { \% к 2012 г. }\end{array}$ & 153,6 & 95,6 \\
\hline 3 & $\begin{array}{l}\text { Индекс физического объема } \\
\text { инвестиций, \% к 2012 г. }\end{array}$ & 130,2 & $31,2 * * *$ \\
\hline 4 & $\begin{array}{l}\text { Трансферты из федерального бюджета, } \\
\text { млрд руб. }\end{array}$ & 19,9 & 9,3 \\
\hline 5 & Уровень общей безработицы, \% & 6,8 & 983,9 \\
\hline 6 & $\begin{array}{l}\text { Среднегодовая численность } \\
\text { постоянного населения, тыс. чел. }\end{array}$ & 958,9 & \\
\hline
\end{tabular}
рятия...

* Источники: Бурятия в цифрах. 2019; ** данные за 2017 г.; *** Закон Республики Бу-

Предполагалось, что общий показатель экономического развития - валовой региональный продукт по прогнозным расчетам в реальном выражении увеличится к 2018 г. на 23 \% по сравнению с 2012 г. Фактически ВРП Республики Бурятия уменьшился почти на $10 \%$.

Еще больший разрыв между прогнозом и действительностью выявлен в промышленном производстве - вместо заявленного увеличения более чем в 1,5 раза произошло снижение показателя. Сходная ситуация наблюдалась и в отношении инвестиций, объем которых за 6 лет снизился более чем на $20 \%$.

Одним из важнейших показателей, характеризующих уровень экономического развития субъекта Российской Федерации, является величина трансфертов из федерального бюджета. Чем меньше значение этого показателя, тем самодостаточней 
является экономика региона. К сожалению, фактическая величина трансфертов в 2018 г. превысила прогнозное значение более чем в 1,5 раза. Республика Бурятия остается глубоко дотационным субъектом Российской Федерации. Доля трансфертов в доходах республиканского бюджета составляет 55,2 \% против 36,1 \% по долгосрочному прогнозу.

Одним из немногих показателей развития Республики Бурятия, в отношении которого фактическое значение было лучше прогнозного, является среднегодовая численность постоянного населения. В 2018 г. она на 24,0 тыс. чел. (2,5 \%) превысила прогнозное значение.

В целом значительные расхождения между прогнозными и фактическими значениями показателей, на наш взгляд, можно объяснить несколькими причинами. Во-первых, чрезмерным оптимизмом разработчиков долгосрочного прогноза. Предполагалось, что в течение всего прогнозного периода темпы роста ВРП республики будут опережать среднероссийские показатели. Следует отметить, что индекс физического объема ВРП по всем субъектам Российской Федерации в 2017 г. составил 105,1 \% против 90,4 \% по Республике Бурятия. Такими же завышенными ожиданиями характеризовались и другие прогнозные показатели. Действительность оказалась гораздо хуже. Не были реализованы некоторые крупные инвестиционные проекты, включая введение в эксплуатацию Озерного ГОКа, продолжение строительства 1-й очереди Улан-Удэнской ТЭЦ-2 в составе 2 энергоблоков, создание особой экономической зоны туристско-рекреационного типа «Байкальская гавань».

Во-вторых, негативное воздействие на экономику Республики Бурятия за прошедшие 6 лет оказали неблагоприятные тенденции в экономическом развитии страны в целом, включая действие санкционных мер стран Запада в отношении России.

Авторами проведен сравнительный анализ среднесрочных прогнозов социально-экономического развития Республики Бурятия и достижения прогнозных показателей с фактическими значениями.

Прогноз социально-экономического развития Республики Бурятия на 2016 г. и на плановый период 2017 и 2018 гг. (далее - прогноз 2016-2018 гг.) разработан по двум вариантам [Постановление Правительства Республики Бурятия от 28 октября 2015 г.]:

- первый вариант (базовый) предполагал сохранение рисков развития экономики республики, продолжение действия санкционных мер в отношении России, слабый рост инвестиционного и потребительского спроса и объемов промышленного производства;

- второй вариант (оптимистичный) основан на более благоприятном сочетании внешних и внутренних факторов, относительной стабильности инвестиционного и потребительского спроса и более высоких темпах роста промышленного производства.

Прогноз социально-экономического развития Республики Бурятия на 2017 г. и на плановый период 2018 и 2019 гг. (далее - прогноз 2017-2019 гг.) также был разработан по двум вариантам [Постановление Правительства Республики Бурятия от 28 октября 2016 г.]. Первый вариант (базовый) основывался на существовавших в то время тенденциях экономики, включая сохранение невысокого инвестиционного спроса, невысоких темпов промышленного производства и потребительского спроca. Второй вариант (целевой) основан на тех же положениях, что и оптимистичный вариант предшествующего прогноза.

Прогноз социально-экономического развития Республики Бурятия на 2018 г. и на плановый период 2019 и 2020 гг. (далее - прогноз 2018-2020 гг.) был разработан по трем вариантам [Постановление Правительства Республики Бурятия от 9 октября 2017 года]. Первый вариант (базовый) основывается на сохранении сложившихся тенденций развития экономики, невысокого инвестиционного и потребительского спроса, низких темпов промышленного производства. Консервативный 
(промежуточный) основан на предпосылке более существенного замедления роста российской экономики и предполагает более низкие темпы экономического роста республики. Целевой вариант предполагает более благоприятное сочетание внешних и внутренних факторов и более высокий рост в экономике, относительную стабильность инвестиционного и потребительского спроса.

По всем трем прогнозам базовыми являлись первые варианты прогноза, которые стали основой при разработке проектов законов Республики Бурятия о республиканском бюджете на среднесрочный период с продолжительностью 3 года. Прогнозные показатели развития экономики Республики Бурятия за 2018 г. по базовым вариантам трех среднесрочных прогнозов в сопоставимых ценах приведены в таблице 2.

Таблица 2

Прогнозные и фактические показатели развития экономики Республики Бурятия за 2018 г., в ценах 2015 г.*

\begin{tabular}{|c|l|c|c|c|c|}
\hline № & \multicolumn{1}{|c|}{ Показатель } & $\begin{array}{c}\text { Прогноз } \\
2016-2018 \text { гг. }\end{array}$ & $\begin{array}{c}\text { Прогно3 } \\
2017-2019 \text { гг. }\end{array}$ & $\begin{array}{c}\text { Прогно3 } \\
2018-2020 \text { гг. }\end{array}$ & $\begin{array}{c}\text { Факт. } \\
\text { знач. }\end{array}$ \\
\hline 1 & $\begin{array}{l}\text { Валовой региональный продукт, } \\
\text { млрд руб.* }\end{array}$ & 198,9 & 187,4 & 193,2 & 184,9 \\
\hline 2 & $\begin{array}{l}\text { Объем отгруженных товаров } \\
\text { по ВЭД** «Добыча полезных } \\
\text { ископаемых», млрд руб. }\end{array}$ & 20,2 & 21,8 & 19,8 & 24,3 \\
\hline 3 & $\begin{array}{l}\text { Объем отгруженных товаров } \\
\text { по ВЭД «Обрабатывающие } \\
\text { производства», млрд руб. }\end{array}$ & 94,0 & 67,2 & 63,0 & 15,2 \\
\hline 4 & $\begin{array}{l}\text { Продукция сельского хозяйства } \\
\text { в хозяйствах всех категорий, } \\
\text { млрд руб. }\end{array}$ & 15,9 & 18,3 & 18,9 & 22,9 \\
\hline 5 & $\begin{array}{l}\text { Объем работ, выполненных по } \\
\text { ВЭД «Строительство», млрд руб. }\end{array}$ & 17,2 & 18,1 & 12,0 & 15 \\
\hline
\end{tabular}

* Данные за 2017 г; ** ВЭД - вид экономической деятельности.

В целом по большинству показателей отклонение фактических значений от прогнозных было значительным. На этом фоне выделяется показатель «объем работ, выполненных по ВЭД “Строительство”», по которому действительное значение почти в 2 раза (на 90 \%) превышало прогнозное, заложенное в самый «свежий» среднесрочный прогноз - 2018-2020 гг.

Наиболее точными оказались прогнозы 2017-2019 гг. и 2018-2020 гг. по показателю «Объем отгруженных товаров по ВЭД “Обрабатывающие производства”», по которым отклонение от фактического значения оказалось относительно небольшим. С другой стороны, очень неточным оказался среднесрочный прогноз 2016-2018 гг., по которому превышение показателя составило почти 50 \%. В определенной степени это можно объяснить резким падением производства и сбыта продукции на Улан-Удэнском авиационном заводе.

Противоположной была ситуация по показателю «Продукция сельского хозяйства в хозяйствах всех категорий». Наибольшие отклонения фактических значений от прогнозных были выявлены в прогнозах 2017-2019 гг. и 2018-2020 гг.

Единственным показателем, по которому фактическое значение превзошло прогнозные, был индикатор «Объем отгруженных товаров по ВЭД “Добыча полезных ископаемых"».

Напротив, по ключевому показателю «Валовой региональный продукт» фактическое значение не достигло прогнозных параметров. Реальное значение ВРП со- 
ставило: 93 \% к прогнозу 2016-2018 гг; 98,7 \% к прогнозу 2017-2019 гг. и 95,7 \% к прогнозу 2018-2020 гг.

В целом, подводя итог, следует отметить недостаточно высокую точность прогнозов, по всей видимости, связанную с переоценкой перспектив развития экономики Республики Бурятия. В условиях фактического отсутствия реализации крупных инвестиционных проектов, которые могли бы стать локомотивом экономического роста республики, трудно ожидать положительных тенденций.

\section{Источники и литература}

Федеральный закон от 28 июня 2014 г. № 172-Ф3 «О стратегическом планировании в Российской Федерации».

Закон Республики Бурятия от 19 декабря 2018 г. № 267-VI «O внесении изменений в Закон Республики Бурятия “О республиканском бюджете на 2018 год и на плановый период 2019 и 2020 годов"».

Постановление Правительства Республики Бурятия от 12 февраля 2013 года № 53 «Об утверждении долгосрочного прогноза социально-экономического развития Республики Бурятия на период до 2030 года».

Постановление Правительства Республики Бурятия от 28 октября 2015 г. № 542 «О прогнозе социально-экономического развития Республики Бурятия на 2016 год и на плановый период 2017 и 2018 годов».

Постановление Правительства Республики Бурятия от 28 октября 2016 г. № 500 «О прогнозе социально-экономического развития Республики Бурятия на 2017 год и на плановый период 2018 и 2019 годов».

Постановление Правительства Республики Бурятия от 9 октября 2017 года № 488 «О прогнозе социально-экономического развития Республики Бурятия на 2018 год и на плановый период 2019 и 2020 годов».

Бурятия в цифрах: стат. сб. / Бурятстат. - Улан-Удэ, 2019. - 217 с.

Потапов Л. В. О региональной системе стратегического планирования / Л. В. Потапов, Б. В. Базаров, 3. Б.-Д. Дондоков // Вестник Бурятского научного центра СО РАН. - 2015. № 1(17). - С. 131-142.

\section{References}

Federal'nyj zakon ot 28 iyunya 2014 g. № 172-FZ «O strategicheskom planirovanii v Rossijskoj Federacii».

Zakon Respubliki Buryatiya ot 19 dekabrya 2018 g. № 267-VI «O vnesenii izmenenij v Zakon Respubliki Buryatiya "O respublikanskom byudzhete na 2018 god i na planovyj period 2019 i 2020 godov"».

Postanovlenie Pravitel’stva Respubliki Buryatiya ot 12 fevralya 2013 goda № 53 «Ob utverzhdenii dolgosrochnogo prognoza social'no-ekonomicheskogo razvitiya Respubliki Buryatiya na period do 2030 goda».

Postanovlenie Pravitel'stva Respubliki Buryatiya ot 28 oktyabrya 2015 g. № 542 «O prognoze social'no-ekonomicheskogo razvitiya Respubliki Buryatiya na 2016 god i na planovyj period 2017 i 2018 godov».

Postanovlenie Pravitel’stva Respubliki Buryatiya ot 28 oktyabrya 2016 g. № 500 «O prognoze social'no-ekonomicheskogo razvitiya Respubliki Buryatiya na 2017 god i na planovyj period 2018 i 2019 godov».

Postanovlenie Pravitel’stva Respubliki Buryatiya ot 9 oktyabrya 2017 goda № 488 «O prognoze social'no-ekonomicheskogo razvitiya Respubliki Buryatiya na 2018 god i na planovyj period 2019 i 2020 godov».

Buryatiya v cifrah: stat. sb. / Buryatstat. - Ulan-Ude, 2019. - 217 s.

Potapov L. V. O regional'noj sisteme strategicheskogo planirovaniya / L. V. Potapov, B. V. Bazarov, Z. B.-D. Dondokov // Vestnik Buryatskogo nauchnogo centra SO RAN. - 2015. № 1(17). - S. 131-142. 